\title{
Tres, tareas para el escritor salvadoreño contemporáneo
}

\footnotetext{
7 res son las tareas que creo debe desempeñar el escritor salvadoreño con temporáneo. En primera instancia, las enunciaré todas; luego, las iré explicando una a una:
}

Primera tarea: Frente a la amnesia colectiva, el escritor ha de intentar ser la memoria imaginística de su grupo humano.

Segunda tarea: Ante la vulgarización y la tosquedad generalizadas, el escritor ha de propugnar el refinamiento espiritual.

Tercera tarea: Frente a una globalización y a una estandarización que convierte todo en una tabla rasa, el escritor ha de presentar el sabio aislamiento.

Empecemos por la primera tarea: Frente a la amnesia colectiva, el escritor ha de intentar ser la memoria imaginística de su grupo humano. Es un hecho patético y comprobado que el salvadoreño, en términos generales, tiene muy poca memoria histórica. Remitámonos a algunos datos que son aleccionadores.

La guerra que acaba de terminar fue para todos nosotros un acontecimiento traumatizante; por eso, quién más quién menos quisiéramos olvidarla, borrarla totalmente de nuestra memoria. Esto es algo natural; pero yo creo que el fenómeno va apuntando a algo más de fondo. Yo percibo una tendencia generalizada a olvidar todo pasado: el pasado reciente y el pasado remoto.

Por ejemplo, la herencia precolombina - pipil, maya o lenca- tiende a ser cada vez más soterrada, arrinconada en los sustratos más hondos de nuestro territorio y de nuestra conciencia -o inconsciencia- colectiva. Esto explicaría hechos tan dramáticos como los ocurridos recientemente: en los terrenos de una urbanización de Antiguo Cuscatlán se descubrieron los cimientos de lo que fue el señorío de Cuscatlán. Personalmente pude constatar el trabajo de rescate que estaban llevando a cabo investigadores y arqueólogos del museo nacional. Sin embargo, en un determinado momento, las excavaciones toparon con sólidos 
intereses económicos, y las estructuras aquellas fueron arrasadas y allanadas por los bulldozers de la compañía constructora.

Total, ¿a quién podrían interesarle unos tetuntes - como dijo el dueño de la compañía urbanizadora- o unos cuantos adobes que ni gracia ni forma tenían? Ciertamente, esto no ocurriría en un país más adelantado que el nuestro. La polvareda y el escándalo que se levantarían a nivel de la opinión pública bastarían para hacer desistir a los urbanistas de su irresponsable labor depredadora.

Un ser humano que no tiene raíces, que no está anclado en un lugar, en una historia, pues entonces es alguien sin verdadera identidad cultural. No se mira ni se remira en los monumentos del pasado, porque no los considera como suyos, como parte de él mismo. A ese tal bien puede imponérsele una cultura extraña, por más estrafalaria y deshumanizadora que sea; porque ese pobre ser tiene una personalidad cultural de mclcocha, amorfa, dispuesta a adoptar el molde que se le imponga desde dentro o desde fuera de su territorio nacional.

El desinterés y desapego de los salvadoreños por lo propio, por lo que debería ser su patrimonio, también se hace extensivo al medio natural. Todos sabemos que El Salvador es el segundo país de América latina —después de Haitímás devastado y depredado en cuanto a recursos naturales. Apenas un $2 \%$ de los bosques originales es lo que nos va quedando... Y, sin embargo, ¿qué hacemos todos nosotros para detener ese proceso de devastación? ¿Nos afecta realmente lo que está pasando?

Junto a la flora, está desapareciendo también loda una rica fauna. Pero, ¿a quién de nosotros le interesa que estén por extinguirse o se hayan extinguido ya especies animales como la danta (o tapir), la guara y el jaguar? Usulután significa: "tierra de los ocelotes"; pero ese animalito sólo en el nombre del departamento va quedando ya. El quetzal estuvo a punto de ser borrado del mapa de El Salvador; de su paso por algunos cerros ha quedado el rastro también en los nombres: Quezaltepeque, "cerro del quetzal" se llama nuestro volcán de San Salvador, porque ahí muy probablemente hubo quetzales.

Es triste constatar algo como esto: a la mayoría de los salvadoreños no les importa que se acaben las loras, los pericos; total, ¿acaso no podemos importarlos de cualquier país de Centroamérica? ¿A qué tanto escándalo?, dice nuestro "sentido común". ¿En qué me afecta a mí que se extingan el garrobo o el tenguereche? $Y$, sin embargo, recordemos lo que dice el cacique Seatle en su famosa carta: lo que ocurra a cualquiera de las especies animales, en cuanto a su acabamiento y extinción, es un reflejo y en espejo de lo que más tarde o más temprano puede ocurrirle al ser humano.

En esta ocasión me interesa a mí escarbar más al fondo de la cuestión... Este distanciamiento e indiferencia con respecto a los tesoros históricos y naturales nos van dando datos claves sobre lo que, un poco pedantemente, podríamos 
llamar un psiquismo colectivo. Al salvadoreño, en general, "le vale" todo aquello que no lo esté afectando muy directamente en su momento presente. En el libro mío Temas salvadoreños he tratado de colarme hasta las raíces de lo que familiar o vulgarmente se ha dado en llamar el "valeverguismo" del salvadoreño. Allá remito a quienes quieran abundar en el tema.

De todas maneras, a este desinterés por un patrimonio histórico y natural que debería ser celosamente preservado, hay que darle un apelativo más apropiado. Para eso, acudamos a al menos un punto de referencia. Copán está en Honduras, a escasos $60 \mathrm{~km}$. de la frontera salvadoreña... Los hondureños —catalogados por nosotros más haraganes y retardados - han sabido conservar aquellas maravillosas ruinas, y hasta el pueblito mismo de Copán es una invitación a internarse en lo sencillo, en lo típico. Resultado: por las calles empedradas, por las aceras y portales bien cuidados circulan chorros de turistas que dejan cantidades enormes de dólares... Como contrapartida, yo no conozco ningún pueblo en El Salvador que sea el equivalente de Copán. Suchitoto, para el caso, es quizás el que más se le podría parecer. Pero, para ir a esa ciudad mágicamente conservada de la depredación humana, hay que pasar por los basureros y lupanares de San Martín; y ahí mismo en Suchitoto no creo que haya muchos hoteles de cinco estrellas.

En suma, ese empecinamiento en olvidar, en echarle tierra a lo viejo, a lo "pueblerino", se traduce en pérdidas económicas para el mismo que entierra y que ulvida. ¿Cómo podemos llamarle, entonces, a esto? Perdónenme, pero para mf a esta tara, en vez de amnesia o algo parecido, habría que llamarla simplemente estupidez. Los salvadoreños o somos o nos hacemos; pero lo cierto es que entre nosotros anda circulando en grandes dosis la idiotez.

Un terror secularmente padecido, de tal manera que haya paralizado las verdaderas facultades de la inteligencia y del razonamiento. Un analfabetismo práctico, presente hasta en los estratos diz que ilustrados de la población. Una haraganería disfrazada de un sobreactivismo, a la postre, improductivo... estas y otras más - como la malnutrición que impide el desarrollo de las neuronas, o una deficiente educación - pueden ser las causas de tal atraso mental colectivo. Pero no es el caso meterme en el tema, y lo dejo para futuras discusiones.

Bueno, frente a este panorama, ¿qué pueden hacer los hombres y mujeres de letras? Entiendo que siendo tan grave el problema la búsqueda de soluciones rebasa el ámbito de lo puramente artístico y literario. Todos los trabajadores de la cultura, todos los profesionales y personas medianamente sensibles deberían tomar cartas en el asunto. Y en este campo, el literario tal vez tenga desventaja ya que su aporte va tirando más al mediano o al largo plazos. De todos modos, puntualicemos algunos mojones.

Corresponde al escritor investigar nuestra historia, rastrear en el pasado (re- 
ciente y remoto) con el propósito de salvar del olvido personajes y hechos que pueden servir como puntos de referencia en la solidificación de una identidad cultural. En esta línea veo yo el aporte de Gavidia; en su obra Ursino le da cuerpo dramático al Partideño, ese Robin Hood nuestro tan de su tiempo y tan actual. Roque Dalton noveliza a Miguelito Mármol, rescatando esa curiosa mezcla de marxismo y de pensamiento mágico, que ha sido tan de muchos de los líderes de izquierda.

Sin embargo, faltan aún personajes y hechos por desenterrar. Monseñor Romero y aun sus asesinos esperan un más de altura tratamiento literario. En este campo, toda la avalancha de literatura testimonial que surgió durante y recién terminada la guerra, es un punto de partida. Yo lo consideraría a ese conjunto más como materia prima que como obras verdaderamente terminales. Aún precisan hechos y personajes un mayor tratamiento técnico, para que vayan adquiriendo su verdadera dimensión literaria.

No puedo extenderme mucho sobre este punto, pero sí es necesario decir al menos que esos personajes y hechos sometidos a la fragua literaria adquieren su verdadero valor literario cuando logran convertirse, grosso modo, en paradigmas, "ejemplos"; es decir, modelos de identificación, puntos de referencia, ideales de conducta, etc., con los cuales el colectivo pueda, de alguna manera, sentirse identificado. La presencia de estos paradigmas es lo que puede contribuir - junto con otras instancias como la religión y la política- a que el colectivo le encuentre un sentido a su lucha por constituirse un espacio y una historia sobre la tierra. El equivalente a este proceso y a esta dinámica es eso que bastante vacía y chuecamente ha querido hacerse con los próceres y con los símbolos patrios. Esas referencias, en la actualidad, sólo sirven para exacerbar nacionalismos infantiles y baratos.

También al escritor - y al artista - le toca poner ante la consideración de todos sus congéneres aquellos aspectos o reductos de la vida natural que deban ser incorporados dentro de la conciencia colectiva. Me refiero con esto a aquellos bosques, parques o enclaves que todavía conservan gran parte de su belleza natural. Sin ir muy lejos, ¿no es eso, precisamente, lo que llevó a cabo Salarrué en sus cuentos? Para mí Salarrué rescató todo ese colorido de la vida campesina y lo plasmó en palabras, como literato, y en formas y colores, como pintor.

En Jaraguá de Napoleón Rodríguez Díaz también se da ese rescate de un ámbito natural: no sólo es la vida de la costa, con sus bellezas naturales pero igualmente como escenario de una terrible lucha por la existencia. También en Jaraguá hay una mención expresa al bosque El Imposible: toda esa fascinaciónrepulsión ante lo arcano está retratada ahí cuando aquellos vaqueros pasan de noche por El Imposible y oyen aullar el viento en las gargantas y quebradas... No entro a discutir aquí si se trata de una literatura ya superada, por regionalista e ingenua. Lo 
que me interesa destacar es que sí cumple una función como establecedora de parámetros de identificación, por lo menos en el ámbito de lo natural.

Si no defendemos lo poco paradisíaco que nos queda a nivel natural es, primero, porque no lo conocemos en toda su dimensión de belleza; y segundo, porque no hacemos el esfuerzo para preservarlo. El escritor puede contribuir, aunque sea en pequeña medida, a que se conozcan esos trozos de paraíso; y puede alentar también una voluntad ciudadana de preservación.

Segunda tarea: Ante la vulgarización y la tosquedad generalizadas, el escritor ha de propender al refinamiento espiritual. Los fenicios son conocidos en la historia de la cultura porque difundieron el alfabeto y porque fueron unos grandes comerciantes y navegantes. Pero también fue característico de los fenicios un arte tosco; aun templo y edificios eran enormes, de paredes lisas. Moloch, su dios monstruoso se alimentaba con la sangre de niños inocentes.

Los griegos también fueron comerciantes muy activos; pero - a diferencia de los fenicios- los griegos no se dejaron comer totalmente por la actividad mercantil. Fueron capaces de traducir la bonanza económica a un arte refinado; supieron invertir para desarrollar una alta cultura. El arte que produjeron los griegos es aún ahora sinónimo de refinamiento; es el arte clásico por antonomasia.

Pues bien, ¿qué tiene que ver esto señalado en torno a griegos y fenicios con el tema que nos ocupa: las tareas que debe desempeñar el escritor salvadoreño contemporáneo? Empecemos por decir que mucho de lo que está ocurriendo en el país apunta más a lo fenicio que a lo griego. Me explicó: ante la vista de todos está el repunte en lo económico. Centros comerciales, colonias residenciales han proliferado como nunca antes. Pero hay un denominador común, sobre todo en las construcciones y edificios comerciales: es lo monstruoso y lo feo lo que parece predominar. Veamos si no, ese mamotreto construido por Simán en el Paseo Escalón; o las horribles cajas para hacer dinero, llamadas Tapachulteca; o las maravillosamente cursis fachadas de bancos como Ahorromet.

En suma, parece ser una triste realidad esa de la proliferación del mal gusto. Edificaciones de gran valor histórico y arquitectónico han sido demolidas para levantar en su lugar unas flamantemente lisas y feas gasolineras de plástico. Y la ciudadanía salvadoreña, ¿ante esto, qué? Pues, en términos generales, yo no exageraría al decir que todo ese montón de edificios constituyen, hoy por hoy, parte del orgullo de ser salvadoreños. Porque, sencillamente, son vistos como símbolos del progreso económico que parece marcar de aquf en adelante a El Salvador.

Y si esto está pasando con la arquitectura monumental, echémosle también un vistazo a la arquitectura personal, a esa en teoría maravillosa construcción llamada ser humano. "¡Estoy borracho y soy muy macho! ¡Soy guanaco a mucha honra!" Este es el grito de guerra que puede escucharse en muchas partes de 
Centroamérica: desde Antigua Guatemala, pasando por Roatán, en Honduras, hasta Varaderos, últimamente, en las playas de Cuba. Hasta allá han llegado para darse a conocer estos apoteósicos desplantes de vulgaridad de nuestros compatriotas guanacos.

Claro que no es sólo eso lo que exporta El Salvador y no es sólo por eso que se le conoce fuera. Hay excepciones muy honrosas que lavan, en parte, la porquería dejada dondequiera por nuestros alegres y despreocupados conciudadanos.

No entro a examinar aquí fenómenos concomitantes como el crónico bayunquismo que nos caracteriza. Ese regusto por el brillo de relojes, pulseras y dientes de oro. Ese atiborramiento de enseres y aparatos eléctricos en que suelen convertirse los dólares habidos en el norte. Dejemos eso sin tocar porque en ese punto hay de otros lares que pueden ganarnos la partida. Ya Octavio Paz en su Laberinto de la soledad hablaba de rasgos muy parecidos entre los pachucos mexicanos.

Quiero detenerme en una imagen, para reflexionar a partir de ella. Es una estampa común ver hombres orinando por todos lados. El colmo fue el otro día: en pleno bulevar de Los Héroes, un ciudadano descargaba en vejiga al lado de un poste de luz. Me llamó la atención que el fulano se tapaba la cara con una mano. Según el, se estaba ocultando, penoso y avergonzado, de las miradas de los transeúntes. "-Estos mis paisanos sí son creativos en estas cosas", me dije. "Inventar la manera más original de disimular la patanada que están haciendo".

La patanada, 1a chabacanería: eso es algo que parece tener marca de fábrica "Made in El Salvador". Sin embargo, yo creo que se trata de un rasgo que no debe asustarnos ni encandalizarnos hipócritamente. Quién más, quién menos, todos hemos entrado en esa dinámica de chabacanería en algún momento de nuestras vidas. Recuerdo que Roque Dalton habla de él mismo como de un ser bifronte, un ser dual. Y esto puede aplicarse a esa doble faceta que acompañó a Roque en su vida y en su obra: por una parte, en él como persona y en algunos de sus libros aparecen resabios de su juvenil "jodarria" y de los desfiles bufos; pero, por otra parte, el mismo Roque Dalton es capaz de elevarse a alturas sublimes en poemas como "Alta hora de la noche" o "A muerte fiel a muerte convidada", entre muchos otros.

El era, como somos todos nosotros, como lo era Quevedo, seres con dos facetas contradictorias. Con un perfil tosco y con otro refinado. $Y$ es que propio de ciertos períodos de formación de las culturas y las nacionalidades, son estos especímenes bifrontes: cuando los griegos aún no se sabían muy diferentes de los cretences, idearon el minotauro: mitad hombre y mitad toro.

En suma -quiero insistir ahora en este punto-, la vulgaridad, el mal gusto pueden considerarse como la escoria, la basura salida naturalmente de los proce- 
sos por los que estamos pasando. Así, si la conformación de una cultura y de una nacionalidad salvadoreñas ha pasado por momentos extremadamente traumáticos y difíciles, pues entonces no es de extrañar que la patanería y el humor procaz se presenten como formas de escape, o de revancha, o recursos irónicos y satíricos de hacer menos trágico lo que ha estado sucediendo. (Recuerdo ese macabro chiste que se le ocurrió durante lo peor de la guerra a alguno de nuestros patanes: apareció la cabeza de un hombre tirada a la orilla de un camino; al rato, ya estaba con un sombrero y con un puro en la boca, asustando a los transeúntes).

Y si estamos ante escoria, ante basura, que incluso forma parte de nosotros mismos; pues lo que nos toca es aprender a reciclarla. Es cierto que quienes tienen poder de decisión, no deben permitir que el mal gusto y lo Kitch sigan normando la construcción de edificios y monumentos (el monumento al Hermano Lejano, más parece un inmenso mingitorio, como recordándonos por qué son conocidos los salvadoreños en el extranjero). Hay basura que de plano hay que botarla y no debe permitirse que infeste nuestras calles y avenidas.

Pero otra clase de escoria, sí debemos reciclarla. Y ahí entra más propiamente la labor de los trabajadores del arte y de la literatura. Hay un cúmulo de experiencias sociales y humanas que actualmente nos están molestando como plastas y como auténticas montañas de basura. Me refiero, por ejemplo, a las maras, al hamponismo. Claro, lo más fácil y aparentemente más obvio: quememos esa basura, acabemos con la plaga de una vez por todas. Sin embargo, eso es injusto y de plano inconsecuente; ya dijimos que esos fenómenos de detritus, de escoria son resultados de procesos en los que se encuentra involucrada toda la sociedad. Las maras, el hamponismo son también culpa de todos nosotros; y, desde esa perspectiva debemos tomar posición. ¿Qué hacemos nosotros para asimilar a esos jóvenes a la vida productiva? ¿Qué podemos ofrecerles para que no sigan escapándose hacia zonas del comportamiento humano en que casi todo se resuelve con los baños de sangre?

En el terreno de lo propiamente literario, también hay una labor de reciclaje por hacer. Para mí, eso que Roque Dalton hizo con el lenguaje de los ladrones y de las prostitutas marca una de las vías. La incorporación de las malas palabras (las cuales no son malas propiamente, sino cuando no es el momento apropiado para decirlas), llevada a cabo con más o menos fortuna según los casos, por escritores como Roberto Cea, es otra vía de ese reciclaje en que deben estar embarcados los escritores nacionales.

Y con esto llegamos al meollo de la tarea que, creo, debe desempeñar el escritor salvadoreño contemporáneo. Frente a la vulgarización ha de propugnar el refinamiento espiritual, decíamos al momento de definir esta tarea. Parece una contradicción con respecto a lo que hemos venido exponiendo en las últimas líneas. Pero -a mi entender- no existe tal contradicción. Refinamiento espiri- 
tual ha de entenderse como la responsabilidad y la finura con que el escritor ha de tomar su función de forjador de la palabra. En ese campo, no deben permitirse contemplaciones. Debe ser disciplinado y riguroso en esa su tarea, ya que es sumamente delicada: delicada porque está tratando con materiales inflamables - para decirlo a través de una imagen-. Si estiliza en demasía su materia prima -l lenguaje, los sucesos a veces terribles, a veces procaces, a veces prosaicos en que se inspira-, pues obtendrá por resultado una obra técnicamente perfecta o académicamente impecable, pero será hueca, vacía de verdadera sustancia humana. Podrá admirarse ahí el ejercicio virtuosista de técnica literaria; pero ese escritor no estará procesando, no estará reciclando verdaderamente la experiencia que está viviendo su gente.

$\mathrm{Si}$, por otro lado, el escritor deja muy en bruto, si transcribe muy directamente los materiales lingüísticos, históricos o antropológicos, pues entonces aportará quizá a la literatura científica de su país, pero no logrará una verdadera aportación en el ámbito de la literatura artística. El arte supone fragua, crisol, supone un adelgazamiento y afinamiento de la palabra, tal que sea capaz de revelar el fondo de sutilidad y de espiritualidad que se encuentra en toda experiencia humana, aun en la más sucia y despreciable.

Sigue siendo válido el postulado: frente a la vulgaridad, frente al descuido e irrespeto en el tratamiento del patrimonio histórico, arquitectónico o lingüístico, el escritor ha de propender al refinamiento espiritual, a la sutilización de la palabra, a la presentación de la misma como algo realmente delicioso de escuchar, de leer o de pronunciar; aunque a veces esa palabra haya sido catalogada como malsonante, vulgar o poco digna de una persona que se precia de poseer una gran altura humana y espiritual.

Tercera tarea: frente a una globalización y a una estandarización que convierten todo en una tabla rasa, el escritor ha de representar el sabio aislamiento. La sociedad moderna presenta múltiples ventajas para todos nosotros; por ejemplo, en un instante podemos conocer lo que acaba de ocurrir en cualquier rincón del planeta, o podemos trasladarnos con relativa facilidad a los antípodas. La tecnología de nuestro tiempo permite la rapidez y la asepsia en todo.

Sin embargo, tenemos que reconocer que estamos dentro de una corriente de globalización que no ofrece perspectivas halagüeñas para el futuro del planeta y de las próximas generaciones. De seguir las cosas como hasta ahora, los recursos naturales se van a agotar irremisiblemente; y, peor aún, el planeta Tierra mismo podría se invivible para el ser humano.

En otras palabras, los procesos destructivos y depredatorios que están operando en la actualidad son los causantes, por ejemplo, de la destrucción de la capa de ozono, del incremento alarmante de la temperatura de la tierra - debido al efecto invernadero-. De modo, pues, que en base a los anteriores datos, 
podemos hacer el siguiente pronóstico: Marte es el futuro de la Tierra; pero, entendámonos: no es que para Marte se vayan a ir los pocos que queden en la Tierra después de la devastación y de la debacle (podría ser una posibilidad, según algunos). No, Marte es el futuro de la Tierra porque ésta puede terminar dentro de pocos lustros como el planeta rojo: árida y desierta, y azotada por tempestades infernales de arena roja.

Según los últimos descubrimientos, el planeta Marte tuvo muy posiblemente agua: las huellas que se ven en su superficie son del mismo tipo que dejan ciertos desbordes de ríos en la Tierra. Pero, más dramático aún: parece que efectivamente hubo vida en Marte hace mil millones de años. ¿Qué quiere decir esto? Pues que en ese planeta pudo haber existido una civilización como la nuestra, hace muchísimo tiempo, y que no fue capaz de administrar sabiamente los recursos naturales. De modo que al convertirse Marte en el desierto que ahora es, acabó por extinguirse aquella civilización también. Marte, pues, es el futuro de la Tierra, así como van las cosas.

Nosotros, en El Salvador, llevamos la delantera en este aspecto. La depredación de la corteza vegetal, la desecación de los mantos acuíferos, nos están llevando a una más pronta consecución de las metas que le esperan a la Tierra toda. ¡Y todavía hay algunos cretinos que se sienten orgullosos de lo rápido que está creciendo el manto de asfalto y de cemento, a costa de la cubierta boscosa y vegetal! $\mathrm{O}$ realmente somos, o nos hacemos pero el problema es absolutamente preocupante.

Hace unos meses estuvo en casa del amigo Roberto Huezo un señor que organiza los foros internacionales de Ecología y Medio Ambiente. Hubo algo que le llamó la atención, porque le dijo a Roberto: “-Quiero que me prestes un termómetro para medir la temperatura ambiente; lo voy a hacer durante los ocho días que estaré hospedado en tu casa; después te digo por qué hago esto". Efectivamente, a los ochos días el señor aquél le dijo al amigo Huezo: "-Te tengo malas noticias: me llamó la atención cuando vine a tu país el hecho de que las noches son muy frías y los días son muy calientes. Ahora lo he comprobado: ciertamente, toda esta semana la temperatura ha bajado sensiblemente durante la noche, y ha subido bastante durante el día. El margen en los cambios de temperatura es muy amplio. $\mathrm{Y}$ eso indica, mi amigo, que tu país será dentro de poco un hermoso desierto..."

Bueno, ésta es la patética realidad que nos espera quizás dentro de unos pocos años. Lo que consuela a los tontos de mi generación es que todo eso apocalíptico ya no lo veremos nosotros, ni quizás nuestros hijos; tal vez a nuestros nietos les toque achicharrarse o buscar los últimos rincones donde haya sombra y agua. 
¿A qué quiero llegar con todo esto? La corriente globalizadora, estandarizadora, mediocrizadora, vulgarizadora es una correntada que ya nadie detiene. Esto es así, nos guste o no nos guste. Se trata de un aluvión que ha agarrado tanta fuerza que ya sólo un milagro podría detenerlo; y los milagros no son muy frecuentes hoy que se diga. Ahora bien, eso no quiere decir que mejor no hacemos nada, y nos sentamos a la orilla del camino, a ver cuándo nos toca que nos arrastre... Yo creo que debe librarse la lucha; cada uno debe asumir su papel, pero actuando con criterio realista, no romántico ni idealista utópico.

Lo más que podemos hacer es crear islas, conformar islotes que, de alguna manera, contengan y detengan el arrastre. Pero, jojo! en esos islotes mantendremos por algún tiempo condiciones que ya se habrán perdido en otros lados; pero - más tarde o más temprano- también esos islotes serán barridos.

Estoy proponiendo con esto la creación de espacios simbólicos pero también reales. Me explico: salvar, por ejemplo, enclaves como el Parque El Imposible, o el Parque Nebuloso de Montecristo o el Parque Deininger, es algo que debemos procurarlo todos. Pero, dado cómo se va desenvolviendo el crecimicnto poblacional, llegará un momento en que esos reductos habrán de desaparecer: frente a la necesidad de tierras para cultivar, pues saldrán sobrando los hábitats de los últimos quetzales y de los rey zope. Sin embargo, hoy por hoy, debemos alimentar a toda costa la ilusión de que la preservación de esos tesoros es posible. Esa persuasión puede darle sentido a nuestro actuar y a nuestro ser, tal como señalé en páginas anteriores.

La conservación de estos últimos reductos de bosques y parques nacionales, se me ocurre a mí que se parece a esas películas de ciencias ficción en las cuales se nos pronostica como escaparatoria para la destrucción a que está siendo sometida la Tierra, la creación de domos, de burbujas gigantes de vidrio, dentro de las cuales se plantan bosques, con el objeto de trasplantarlos después en otros planetas. Así me siento a veces yo: viajando en un domo en el que hay árboles con ardillas y pájaros, pero condenados a muerte.

Decía antes que deben fabricarse espacios simbólicos, donde se cree la ilusión (en el sentido de: engaño para los sentidos, pero también de anhelo profurido) de que no todo va camino de la pronta destrucción. Vana ilusión, ciertamente: pero - de nuevo- hay que hacer la lucha. En esos espacios que he llamado simbólicos ha de recluirse quien quiera tomar contacto con su mundo interior, con su ámbito más sutil y espiritual. Propongo, entonces, el ejercicio literario (escribir o leer) como una forma de meditación. Ahí, en ese gabinete, en ese laboratorio de alquimista - donde el espíritu se siente volar a sus anchas, sin la urgencias de la vida cotidiana - han de fraguarse las palabras que el literato se ha de decir a sí mismo y a decirse a sus semejantes. 
Desde luego que es esta una labor que no sólo corresponde a los letrados, tal como expliqué unos párrafos antes. Pero lo propio y específico del manipulador de palabras escritas -el artista literato, el poeta - es presentar el fruto de su trabajo, sus obras, como auténticos remansos, como espacios simbólicos donde es posible sustraerse a esa riada de estupidización y de urgencias inmediatas. Ahí, en esos domos, donde se vive la ilusión de que la vida es más intensa incluso que en la vida real, ahí es donde la palabra adquiere toda su dimensión sagrada. Y no porque estemos ante libros sacros: la Biblia, los Vedas o el Corán. Es sagrada porque aunque se trate de la novela más rosa y más cursi, o del poema más romántico, es palabra que se lee o se escucha con respeto, con los sentidos más interiores del alma.

Termino esta última reflexión sobre las tareas del escritor salvadoreño haciendo votos porque el escritor sea alguien que verdaderamente contribuya a hacer más humanos y más vivibles los quizás pocos años que nos quedan de vida, como país y como especie humana. Por otra parte, desearía de todo corazón que estas reflexiones, a mi pesar apocalípticas, de ninguna manera se vieran cumplidas y realizadas... 